\title{
Investigating the structural relationships between food image, food satisfaction, culinary quality, and behavioral intentions: the case of Malaysia
}

\begin{abstract}
This study was designed to test a theoretical model determining the relationships among tourists' perceived food image, food satisfaction, culinary quality, and behavioral intentions. The structural relationships between the variables were examined by adopting a structural equation modeling (SEM) approach, and the empirical data was collected in Malaysia. Analysis of findings revealed that (a) tourists' perceived food image played a role in directly influencing food satisfaction and quality of culinary experience (culinary quality); (b) food image influenced tourists' behavioral intentions through culinary quality; (c) tourist satisfaction with their food experience directly affected perceived quality of their culinary experience and behavioral intentions; and (d) tourists' behavioral intentions were directly affected by their evaluation of culinary quality. This study concluded that food was an imperative contributor in destination tourism due to its capability in influencing tourists' perceived image, food satisfaction, culinary quality, and consequently impacting tourists' behaviors in the selection of a travel destination.
\end{abstract}

Keyword: Food image; Food satisfaction; Culinary quality; Behavioral intentions; Culinary tourism; Structural equation modeling (SEM) 